\title{
siRNA directed against TrkA sensitizes human pancreatic cancer cells to apoptosis induced by gemcitabine through an inactivation of PI3K/Akt-dependent pathway
}

\author{
DAPENG LIU ${ }^{1 *}$, YONG ZHANG $^{1 *}$, CHENGXUE DANG $^{1}$, QINGYONG MA $^{2}$, WOO LEE $^{3}$ and WUKE CHEN ${ }^{1}$ \\ Departments of ${ }^{1}$ Surgical Oncology and ${ }^{2}$ Hepatobiliary Surgery, First Hospital of Xi'an Jiaotong University, \\ 710061 Xi'an, P.R. China; ${ }^{3}$ Department of Oncology, Molecular Genetics Laboratory, \\ Georgetown University Medical Center, Washington, DC 20007, USA
}

Received March 5, 2007; Accepted May 7, 2007

\begin{abstract}
Previously, we have documented that the aggressive and highly metastatic behavior of pancreatic cancer may be due to the aberrant expression of nerve growth factor (NGF) and its high-affinity receptor, proto-oncogene TrkA. In this study, we sought to determine the effect of suppressing TrkA expression on pancreatic cancer chemosensitivity to gemcitabine. Human pancreatic cancer cell lines PANC-1, MIA-PaCa-2 and ASPC-1 were studied. The expression and kinase activity of TrkA were determined by Western blot analysis and in vitro kinase assay respectively. RNA interference was used to suppress TrkA expression. Gemcitabineinduced cytotoxicity was determined by tetrazolium reduction assay and caspase profiling was performed. The effect of TrkA-specific siRNA on PI3K/Akt activity was also quantified. TrkA expression and kinase activity in cell lines were directly correlated with gemcitabine chemoresistance. TrkA-specific siRNA suppressed TrkA expression and kinase activity, and furthermore increased gemcitabine-induced, caspase-mediated apoptosis. PI3K/Akt activity was decreased by suppression of TrkA expression. Taken together, these data demonstrated that $\operatorname{Trk} A$ is a determinant of pancreatic adenocarcinoma chemoresistance and PI3K/Akt is a key signaling component by which NGF activation of the TrkA signal transduction pathway protects pancreatic cancer cells from chemotherapyinduced cell death.
\end{abstract}

\section{Introduction}

Pancreatic cancer is a lethal disease. Despite significant advances in diagnosis, staging and surgical management of

Correspondence to: Dr Dapeng Liu, Department of Surgical Oncology, First Hospital of Xi'an Jiaotong University, 1 Jiankang Road, 710061 Xi'an, P.R. China

E-mail: sage2001china@yahoo.com.cn

${ }^{*}$ Contributed equally

Key words: siRNA, TrkA, PI3K/Akt, pancreatic cancer the disease, $<10 \%$ of patients survive for more than a year from the time of diagnosis $(1,2)$. The largely refractory response to chemotherapy is a common feature of this disease, and even the principal therapeutic agent, the nucleoside analogue gemcitabine ( 2 ', 2 '-difluorodeoxycytidine), only marginally affects clinical outcomes (3). Therefore, further understanding of the chemoresistance mechanisms present in pancreatic cancer cells remains a high priority in efforts to define better targets for therapeutic intervention.

TrkA, the proto-oncogene Trks encoded high-affinity receptor tyrosine kinase of nerve growth factor (NGF) has been shown to be associated with malignant cellular behavior in a variety of human cancers (4-6). Recently, we have shown that the expression of the NGF and its tyrosine kinase receptor TrkA are often detected in pancreatic cancers derived from patients with an unfavorable prognosis, and furthermore NGF activation of the TrkA signal transduction pathway blocked the cytotoxic effects of chemotherapeutic drugs (4). Others previous studies indicated that inhibition of PI3K using the structurally distinct inhibitors of PI3K (wortmannin and LY294002) enhanced gemcitabine-induced apoptosis in pancreatic cancer cell lines. Akt is an important downstream target of PI3K and functions to regulate cell survival, proliferation and protein synthesis. In this study, we tested the hypothesis that Akt is a key downstream target by which the NGF/TrkA pathway attenuates the effects of chemotherapy in pancreatic cancer cells and that suppression of TrkA/PI3K/ Akt pathway would enhance pancreatic cancer chemosensitivity to gemcitabine.

\section{Materials and methods}

Cell cultures and conditions. Human pancreatic cancer cells were routinely cultured in DMEM (PANC-1 and MIA-PaCa-2) or RPMI-1640 (ASPC-1) supplemented with 10\% fetal bovine serum (FBS, Gibco BRL), 100 units/ml penicillin, and $100 \mu \mathrm{g} /$ $\mathrm{ml}$ streptomycin (complete medium) at $37^{\circ} \mathrm{C}$ in $95 \%$ air and $5 \% \mathrm{CO}_{2}$.

Apoptosis and cell survival analysis. Cell proliferation was determined by 3-(4,5-dimethylthiazol-2-yl)-2,5-diphenyltetra- 
zolium bromide (MTT) assay (Trevigen Inc.) in accordance with the manufacturer's instructions. Logarithmically growing cells were plated at $5 \times 10^{3}$ cells per well in 96-well plates, and allowed to adhere overnight, then cultured in the presence or absence of gemcitabine (2',2'-diflurodeoxycytidine; Eli Lilly \& Co., Indianapolis, IN). Gemcitabine-induced cytotoxicity was determined after $48 \mathrm{~h}$ of exposure. Plates were read using a Vmax microplate spectrophotometer (Molecular Devices) at a wavelength of $570 \mathrm{~nm}$ corrected to $650 \mathrm{~nm}$ and normalized to controls. Each independent experiment was performed 3 times, with 10 determinations for each condition tested. The concentration of gemcitabine required to inhibit proliferation by $50 \%\left(\mathrm{IC}_{50}\right)$ was calculated from these results. Alternatively, cells were harvested as above, and viable and dead cells were counted using trypan blue exclusion (Gibco-BRL). After treatment, cells were washed, resuspended in $0.5 \mathrm{ml}$ of $\mathrm{PBS}$, and $1 \mu \mathrm{l} / \mathrm{ml}$ of the green fluorescent dye YO-PRO-1 and propidium iodide were added (Vybrant Apoptosis Assay Kit \#4, Molecular Probes). Cells were incubated for $30 \mathrm{~min}$ on ice then analyzed by flow cytometry (FACScan, Becton-Dickinson), measuring fluorescence emission at 530 and $575 \mathrm{~nm}$. Cells stained with YOPRO-1 were counted as apoptotic; necrotic cells stained with propidium iodide. The number of apoptotic cells was divided by the total number of cells (minimum of $10^{4}$ cells), giving the apoptotic fraction. Data were analyzed using CellQuest software (Becton-Dickinson). The BD ApoAlert fluorometric Caspase Assay Plate (BD Biosciences Clontech) was then used for assessing caspase 3 activity. After harvesting the whole cell lysates, plates were read (excitation $360 \mathrm{~nm}$; emission $480 \mathrm{~nm}$ ) using a CytoFluor 4000 multiwell fluorescence plate reader (Applied Biosystems). All measurements were performed in triplicate, each with 4 determinations for each condition.

siRNA transfection. Validated human TrkA-specific and control siRNAs were purchased from Biocompare Inc. (SMARTpool, Charlottesville, VA). siRNAs were dissolved in buffer (100 $\mathrm{mM}$ potassium acetate, $30 \mathrm{nM}$ HEPESpotassium hydroxide, $2 \mathrm{nM}$ magnesium acetate, $\mathrm{pH}$ 7.4) to a final concentration of $20 \mu \mathrm{M}$, heated to $90^{\circ} \mathrm{C}$ for $60 \mathrm{sec}$ and incubated at $37^{\circ} \mathrm{C}$ for $60 \mathrm{~min}$ before use to disrupt any higher order aggregates formed during synthesis. Cells were plated into 35-mm, 6-well trays and allowed to adhere for $24 \mathrm{~h}$. In all, $8 \mu 1$ siPORT Amine transfection reagent (Ambion Inc.) per well was added to serum-free medium for a final complexing volume of $200 \mu 1$, vortexed and incubated at room temperature for $15 \mathrm{~min}$. The transfection reagent/siRNA complexes were added to the wells containing $800 \mu 1$ medium with $10 \%$ FBS and incubated in normal cell culture conditions for $6 \mathrm{~h}$, after which $1 \mathrm{ml}$ Dulbecco's Modified Eagle Medium containing $10 \%$ FBS was added.

Western blot analysis. Cells $\left(2 \times 10^{6}\right)$ were washed twice in ice-cold PBS and then incubated with $300 \mu 1$ of lysis buffer [1\% Triton X-100, 0.1\% SDS, $50 \mathrm{mM}$ Tris ( $\mathrm{pH} 8.0), 150 \mathrm{mM}$ $\mathrm{NaCl}, 1 \mathrm{mM}$ phenylmethylsulfonyl fluoride, $0.1 \mathrm{mM} \mathrm{NaVO}_{4}$, $0.1 \mathrm{mM}$ benzamidine, $5 \mu \mathrm{g} / \mathrm{ml}$ leupeptin and $5 \mu \mathrm{g} / \mathrm{ml}$ aprotinin] for $5 \mathrm{~min}$ on ice. Whole cell lysates were clarified by centrifugation at $15000 \mathrm{rpm}$ for $15 \mathrm{~min}$ at $4^{\circ} \mathrm{C}$. The protein concen- tration was determined using the Bradford protein assay (Bio-Rad Laboratory, Richmond, CA, USA) with bovine serum albumin as a standard protein. Thirty micrograms of protein was separated by electrophoresis on a sodium dodecyl sulfate-polyacrylamide gel (12\% gel). After electrophoresis, proteins were transferred to nitrocellulose membrane. After $1 \mathrm{~h}$ incubation in a blocking solution (5\% non-fat dry milk in PBS-0.5\% Tween-20), the membrane was blotted with the anti-TrkA polyclonal antibody (1:200, sc-118, Santa Cruz, CA) and an anti-B-actin monoclonal antibody (1:1000; AC15, Sigma, St. Louis, MO, USA). The blots were developed with peroxidase-labeled secondary antibodies. After extensive washing and incubating with the Enhanced Chemiluminescence Plus detection reagent for $5 \mathrm{~min}$, protected from light, specific bands were detected using a developer, in dark by exposing it to autoradiography film: Hyperfilm Enhanced Chemiluminescence (Amersham Biosciences) for suitable durations of time. Blots were performed in triplicate. Mean densitometric values $( \pm \mathrm{SD})$ are shown.

TrkA tyrosine kinase and Akt kinase assay. For detection of phosphorylation of signaling kinases, cells were first cultured in complete medium and subsequently incubated in medium with $0.5 \%$ FBS for $24 \mathrm{~h}$. Cells were then treated with $100 \mathrm{ng} /$ $\mathrm{ml}$ NGF for $15 \mathrm{~min}$. Cells were lysed, protein was extracted, and the concentration was measured as described above. TrkA tyrosine kinase activity was determined using a commercially available kinase assay kit (Sigma), according to the manufacturer's instructions. TrkA immunoprecipitates $(20 \mu \mathrm{g}$ total protein) were prepared using anti-TrkA polyclonal antibody immobilized onto protein $G$ sepharose beads (Zymed Laboratories Inc.). Immunoprecipitates were washed and dissolved in tyrosine kinase buffer (final solution containing $0.3 \mathrm{mM}$ ATP) and incubated for $30 \mathrm{~min}$ in 96-well plates coated with tyrosine kinase substrate solution (poly-Glu-Tyr). Phosphorylated substrate was quantified by chromogenic detection using horseradish peroxidase-conjugated antiphosphotyrosine antibody. Optical densities were determined at $492 \mathrm{~nm}$ using a Vmax microplate spectrophotometer. TrkA kinase activity was compared with an epidermal growth factor receptor standard. Kinase assays were performed in triplicate with four determinations per condition. Akt activity was quantified using a commercially available non-radioactive in vitro kinase assay, in accordance with the manufacturer's instructions (Cell Signaling Technology). Akt was immunoprecipitated from $200 \mu 1$ cell lysates containing equal total protein. The resulting immunoprecipitates were incubated with glycogen synthase kinase-3 (GSK-3) fusion protein in the presence of ATP and kinase buffer. Phosphorylation of GSK-3, a physiologic target of Akt, was measured by Western blot using antiphospho-GSK-3 $\alpha / 3$ (Ser-21/9) antibody, and densitometric analysis of the stained bands was performed using ImageMaster software (Pharmacia Biotech). Mean values from three independent experiments with three samples per group are shown.

Statistical analysis. Statistical analyses were performed using SPSS-PC package (version 13.0; SPSS, Chicago, IL). The data are expressed as means $\pm \mathrm{SD}$. Analysis was performed using ANOVA, unpaired t-test, and Mann-Whitney U test for 
A

PANC-1 MIA-Pa-Ca-2 ASPC-1 PANC-1 MIA-Pa-Ca-2 ASPC-1

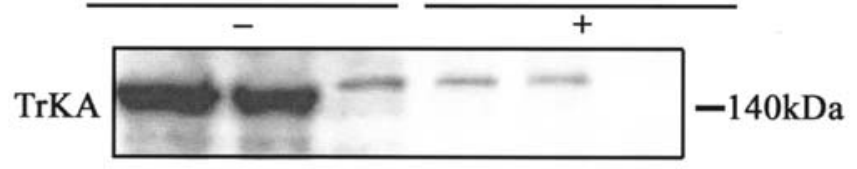

Actin

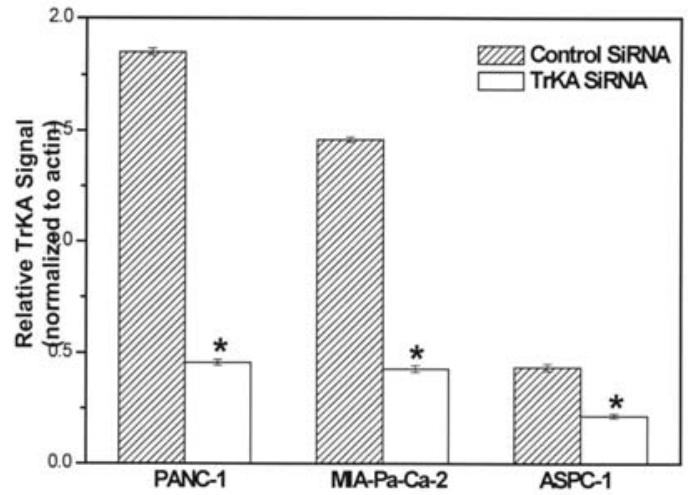

B

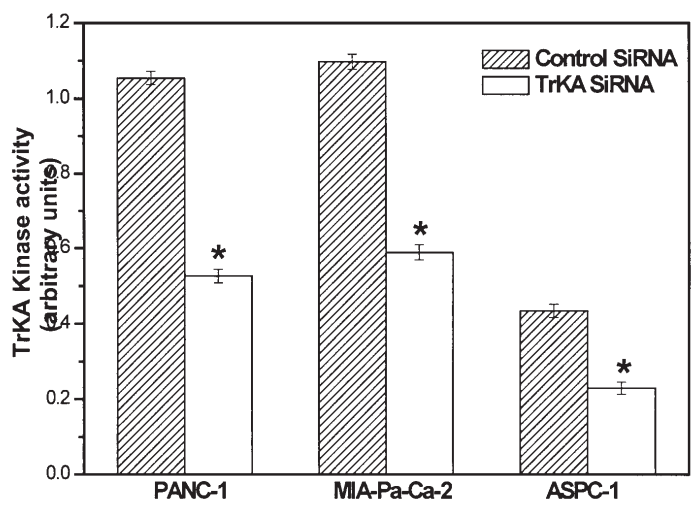

Figure 1. TrkA expression and kinase activity were quantified in PANC-1, MIA-Pa-Ca-2, and ASPC-1 human pancreatic cancer cell lines by Western blot (A), (representative blot with mean densitometry values) and in vitro kinase assay (B), respectively, $96 \mathrm{~h}$ after transfection of control siRNA or transfection of TrkA-specific siRNA. Baseline TrkA expression and kinase activity were higher in PANC-1 and MIA-Pa-Ca-2, which have greater chemoresistance than ASPC-1. TrkA expression and kinase levels showed no difference between untreated cells and those transfected with control siRNA. TrkA-specific siRNA suppressed TrkA protein expression and kinase activity. In each case, values are means $( \pm \mathrm{SD})$ of three independent determinations, ${ }^{*} \mathrm{p}<0.05$ versus control siRNA.

non-parametric data. P-values of $<0.05$ were considered to be statistically significant.

\section{Results and Discussion}

TrkA overexpression is associated with greater gemcitabine chemoresistance. Aberrant expression of TrkA receptor kinases and enhanced expression of NGF has been implicated in the development and progression of variety of human cancers such as prostatic cancer (5), pancreatic cancer (4), breast cancer (6), thyroid papillary carcinomas (7) as well as
Table I. Gemcitabine chemoresistance is greater in cell lines with relatively higher TrkA protein expression.

\begin{tabular}{lcc}
\hline Cell line & $\begin{array}{c}\text { Gemcitabine } \\
\mathrm{IC}_{50}(\mathrm{nM})\end{array}$ & $\begin{array}{c}\text { Relative TrkA expression } \\
\text { (arbitrary units) }\end{array}$ \\
\hline PANC-1 & 49.7 & 1.85 \\
MIA-PaCa-2 & 42.6 & 1.45 \\
ASPC-1 & 12.6 & 0.43 \\
\hline
\end{tabular}

$\mathrm{R}^{2}=0.99$ (Spearman correlation) between gemcitabine $\mathrm{IC}_{50}$ and relative TrkA expression. $\mathrm{IC}_{50}$, concentration required to inhibit proliferation by $50 \%$.

in acute myeloid leukemia (8), and furthermore patients whose carcinoma expression high levels of TrkA have an unfavorable prognosis. Our previous studies indicated that NGF activation of the TrkA signal transduction pathway may block the cytotoxic effects of chemotherapeutic drugs in pancreatic cancer (4). In this study, we demonstrate that levels of TrkA expression were highest in PANC-1, MIA-PaCa-2, cell lines with a higher degree of gemcitabine chemoresistance than ASPC-1, which expressed TrkA at lower levels (Fig. 1A, Table I). We confirmed higher TrkA kinase activity in PANC-1 and MIA-PaCa-2, compared with ASPC-1 (Fig. 1B). The gemcitabine $\mathrm{IC}_{50}$ for each cell line is shown in Table I. This finding indicated that TrkA overexpression may be responsible for NGF signal transduction pathway that protects pancreatic cancer cells from chemotherapy-induced cell death.

TrkA-specific siRNA suppresses TrkA expression. RNA interference is emerging as a powerful technique for the specific inhibition of expression of individual genes at the posttranscriptional level (9). Therefore, TrkA-specific siRNA was transfected with pancreatic cancer cell lines. We confirmed suppression of TrkA protein expression by Western blot analysis (Fig. 1A). TrkA-specific siRNA suppressed TrkA expression by up to $83 \%$, commencing within $24 \mathrm{~h}$ of transfection and persisting at this level $96 \mathrm{~h}$ post-transfection. Suppression of TrkA tyrosine kinase activity by treatment with TrkA-specific siRNA was confirmed by in vitro kinase assay (Fig. 1B). Control siRNA had no effect on either TrkA expression or kinase activity. Treatment with either siRNA did not affect expression of actin, indicating that non-specific suppression of protein expression did not occur. These results demonstrated that TrkA-siRNA was effective in inhibiting the biological function of TrkA.

Inhibition of TrkA expression enhances gemcitabine-induced cytotoxicity. Forty-eight hours after siRNA transfection, cells were exposed to $0-10 \mu \mathrm{M}$ gemcitabine for further 48 hours. The $\mathrm{IC}_{50}$ was calculated from MTT cytotoxicity assay data. TrkA siRNA suppressed the gemcitabine $\mathrm{IC}_{50}$ in each of the three cell lines; control siRNA transfection had no effect on the gemcitabine $\mathrm{IC}_{50}$ (Fig. 2). The increase in gemcitabineinduced cytotoxicity after transfection of TrkA-specific siRNA was accompanied by marked increases in the apoptotic 


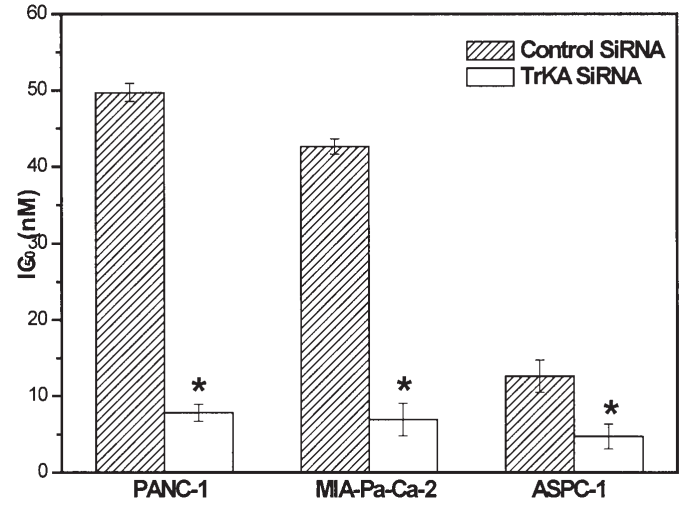

Figure 2. TrkA-specific siRNA promotes gemcitabine-induced cytotoxicity. The gemcitabine $\mathrm{IC}_{50}$ was determined by MTT assay after exposure to gemcitabine for $48 \mathrm{~h}$. Treatment with TrkA-specific siRNA decreased the gemcitabine $\mathrm{IC}_{50}$ of each cell line. Experiments were performed in triplicate with 10 determinations per condition. ${ }^{*} \mathrm{p}<0.05$ versus control siRNA. $\mathrm{IC}_{50}$, concentration required to inhibit proliferation by $50 \%$; MTT, 3- $(4,5-$ dimethylthiazol-2- yl)-2,5-diphenyltetrazolium bromide.

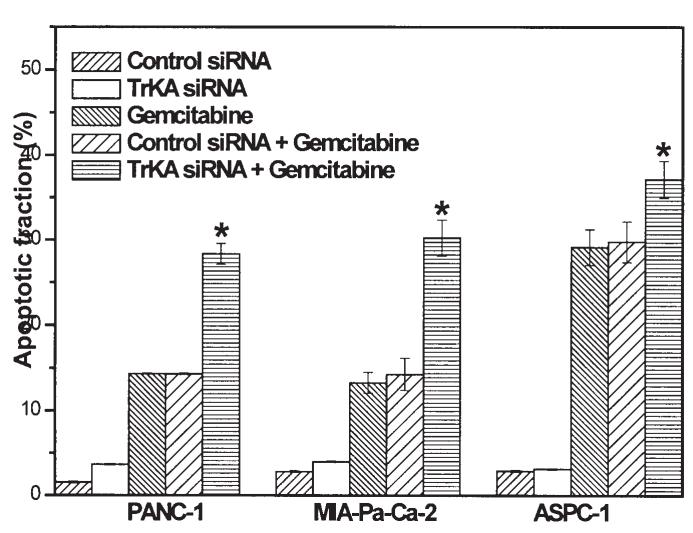

Figure 3. TrkA-specific siRNA increases gemcitabine-induced apoptosis. The apoptotic fraction of cells induced by exposure to $1 \mu \mathrm{M}$ gemcitabine for $48 \mathrm{~h}$ was quantified by flow cytometry after green fluorescent dye YO-PRO-1 and propidium iodide staining. Control siRNA did not affect gemcitabineinduced apoptosis. Four determinations were used per condition and experiments were performed in triplicate. ${ }^{*} \mathrm{p}<0.05$ versus control siRNA.

fraction of cells. Control siRNA had no significant effect on the gemcitabine-induced apoptotic fraction (Fig. 3). The feasibility of using siRNA as a mediator of chemosensitization has been shown by previous studies (10-14) and the contemporary paradigm for anticancer drug development has moved toward target-directed therapies based on a more comprehensive understanding of cancer biology, rather than empirical discovery.

TrkA-specific siRNA enhances gemcitabine-induced activation of caspase 3. Gemcitabine induces apoptosis in tumor cells through caspase activation (15-17). So we sought to determine the effect of TrkA-specific siRNA on activity of effector caspase 3 after exposure to gemcitabine for $48 \mathrm{~h}$. Gemcitabineinduced caspase 3 activation was markedly increased after transfection of TrkA-specific siRNA, but was unaffected after transfection of control siRNA (Fig. 4). These results clearly demonstrated that inactivation of TrkA sensitizes human

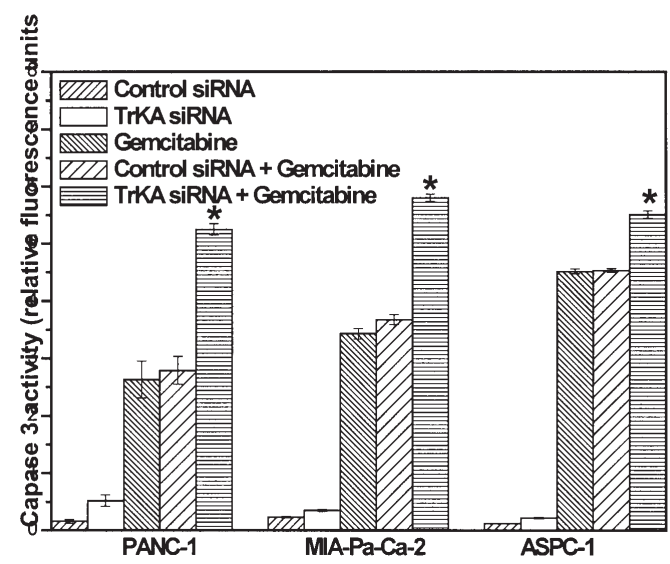

Figure 4. TrkA-specific siRNA increases gemcitabine-induced caspase 3 activation. Caspase 3 activity was quantified by fluorometric assay. Treatment with TrkA-specific siRNA markedly augmented gemcitabine-induced caspase 3 activation. Control siRNA had no significant effect on caspase 3 activity. Values are means of three independent experiments. Four determinations were used per condition. ${ }^{*} \mathrm{p}<0.05$ versus control siRNA.
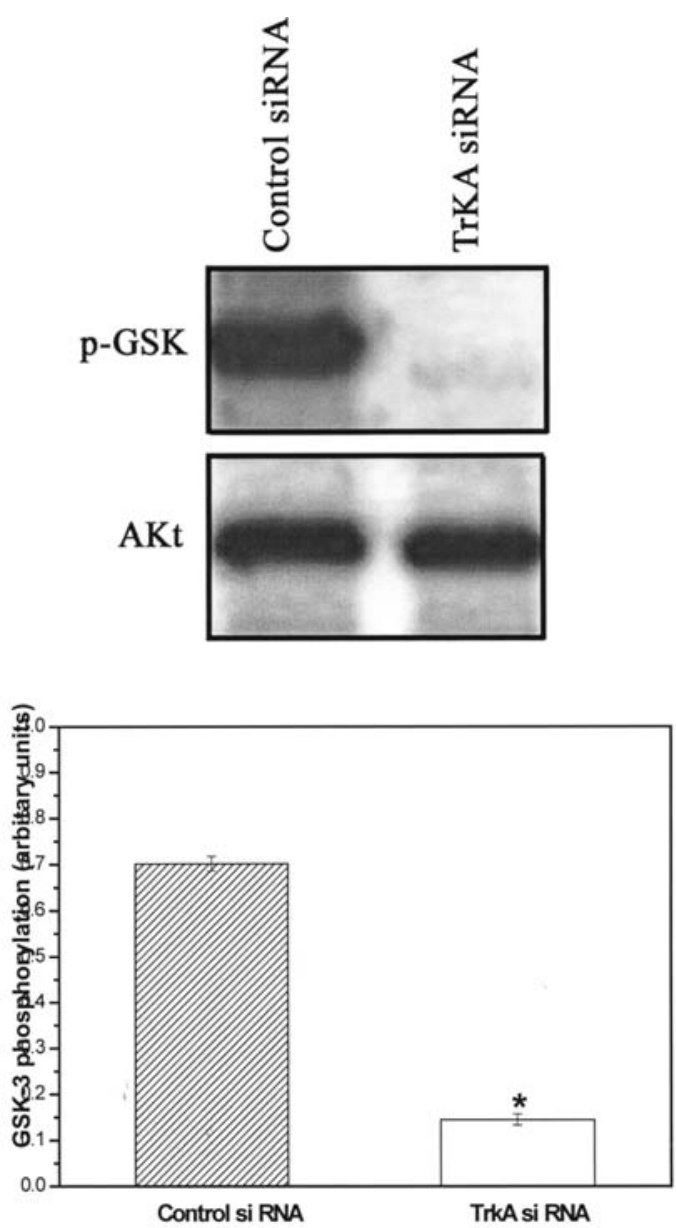

Figure 5. TrkA gene silencing suppresses Akt activity. Akt activity was assessed in PANC-1 cells $96 \mathrm{~h}$ after transfection with control and TrkAspecific siRNA. Suppression of TrkA expression inhibited Akt activity, determined by in vitro kinase assay. Total Akt levels were unaffected. Values are means $( \pm \mathrm{SD})$ of three independent experiments performed in triplicate. ${ }^{*} \mathrm{p}<0.05$ versus control siRNA.

pancreatic cancer cells to caspase-mediated apoptosis induced by gemcitabine. Akt is reported to inhibit activation of initiator 
caspase 9 and effector caspase 3, at a post-mitochondrial level, protecting cells from apoptosis (18). The decrease in Akt activity we observed after transfection of TrkA-specific siRNA may contribute to the increase in gemcitabine-induced, caspase-mediated activity and apoptosis as showed below.

Akt activity is suppressed by inhibition of TrkA expression. Bondar et al demonstrated recently that PI3K/Akt pathway is constitutively activated in a majority of human pancreatic cell lines (19). Moreover, $\mathrm{Ng}$ et al have suggested that PI3K inhibitors may have therapeutic potential when used in combination with cytotoxic agents in reversing drug resistance in pancreatic cancer patients (20). Considering Akt is an important downstream target of PI3K and functions to regulate cell survival, proliferation, and protein synthesis we examined the effect of suppression of TrkA expression on Akt activity using a GSK-3 fusion protein phosphorylation assay, after transfection of TrkA-specific and control siRNA. Transfection of TrkA-specific siRNA resulted in suppression of Akt activity in PANC-1 cell line. Control siRNA had no effect on Akt activity (Fig. 5). Similar results were obtained $48 \mathrm{~h}$ after siRNA transfection. Results indicated that inhibition of TrkA expression constitutively inactive PI3K/ Akt significantly enforced apoptosis induced by gemcitabine.

To summarize, we showed for the first time that TrkAspecific siRNA enhances pancreatic cancer gemcitabine chemosensitivity by promoting caspase-mediated apoptosis through an inactivation of PI3K/Akt-dependent pathway. These findings raise the possibility that novel combined pharmacologic inhibitors of TrkA/PI3K/Akt may enhance the effectiveness of chemotherapeutic agents in the treatment of pancreatic cancer.

\section{References}

1. Gudjonsson B: Cancer of the pancreas. Fifty years of surgery. Cancer 60: 2284-2303, 1987.

2. Magistrelli P, Antinori A, Crucitti A, La Greca A, Masetti R, Coppola R, Nuzzo G and Picciocchi A: Prognostic factors after surgical resection for pancreatic carcinoma. J Surg Oncol 74: 36-40, 2000.

3. Burris HA III, Moore MJ, Andersen J, Green MR, Rothenberg ML, Modiano MR, Cripps MC, Portenoy RK, Storniolo AM, Tarassoff P, Nelson R, Dorr FA, Stephens CD and von Hoff DD: Improvements in survival and clinical benefit with gemcitabine as first-line therapy for patients with advanced pancreas cancer: a randomized trial. J Clin Oncol 15: 2403-2413, 1997.

4. Zhang Y, Dang C, Ma Q and Shimahara Y: Expression of nerve growth factor receptors and their prognostic value in human pancreatic cancer. Oncol Rep 14: 161-171, 2005.

5. Sanchez C, Clementi M, Benitez D, Contreras H, Huidobro C and Castellon E: Effect of GnRH analogs on the expression of TrkA and p75 neurotrophin receptors in primary cell cultures from human prostate adenocarcinoma. Prostate 65: 195-202, 2005 .
6. Dolle L, El Yazidi-Belkoura I, Adriaenssens E, Nurcombe V and Hondermarck H: Nerve growth factor overexpression and autocrine loop in breast cancer cells. Oncogene 22: 5592-5601, 2003.

7. Lind DS, Hochwald SN, Malaty J, Rekkas S, Hebig P, Mishra G, Moldawer LL, Copeland EM III and Mackay S: Nuclear factor-kappa B is upregulated in colorectal cancer. Surgery 130: 363-369, 2001.

8. Nabhan C, Gajria D, Krett NL, Gandhi V, Ghias K and Rosen ST: Caspase activation is required for gemcitabine activity in multiple myeloma cell lines. Mol Cancer Ther 1: 1221-1227, 2002.

9. Xu ZW, Friess H, Buchler MW and Solioz M: Overexpression of Bax sensitizes human pancreatic cancer cells to apoptosis induced by chemotherapeutic agents. Cancer Chemother Pharmacol 49: 504-510, 2002.

10. Duxbury MS, Ito H, Benoit E, Zinner MJ, Ashley SW and Whang EE: RNA interference targeting focal adhesion kinase enhances pancreatic adenocarcinoma gemcitabine chemosensitivity. Biochem Biophys Res Commun 311: 786-792, 2003.

11. Duxbury MS, Ito H, Zinner MJ, Ashley SW and Whang EE: siRNA directed against $\mathrm{c}-\mathrm{Src}$ enhances pancreatic adenocarcinoma cell gemcitabine chemosensitivity. J Am Coll Surg 198: 953-959, 2004

12. Collis SJ, Swartz MJ, Nelson WG and De Weese TL: Enhanced radiation and chemotherapy-mediated cell killing of human cancer cells by small inhibitory RNA silencing of DNA repair factors. Cancer Res 63: 1550-1554, 2003.

13. Wu H, Hait WN and Yang JM: Small interfering RNA-induced suppression of MDR1 (P-glycoprotein) restores sensitivity to multidrug-resistant cancer cells. Cancer Res 63: 1515-1519, 2003.

14. Chang IY, Kim MH, Kim HB, Lee DY, Kim SH, Kim HY and You HJ: Small interfering RNA-induced suppression of ERCC1 enhances sensitivity of human cancer cells to cisplatin. Biochem Biophys Res Commun 327: 225-233, 2005.

15. Eguchi M, Eguchi-Ishimae M, Tojo A, Morishita K, Suzuki K, Sato Y, Kudoh S, Tanaka K, Setoyama M, Nagamura F, Asano S and Kamada N: Fusion of ETV6 to neurotrophin-3 receptor TRKC in acute myeloid leukemia with $\mathrm{t}(12 ; 15)(\mathrm{p} 13 ; \mathrm{q} 25)$. Blood 93: 1355-1363, 1999.

16. Reuther GW, Lambert QT, Caligiuri MA and Der CJ Identification and characterization of an activating TrkA deletion mutation in acute myeloid leukemia. Mol Cell Biol 20: 8655-8666, 2000

17. Shi Y: Mammalian: RNAi for the masses. Trends Genet 19: 9-12, 2003.

18. Zhou H, Li XM, Meinkoth J and Pittman RN: Akt regulates cell survival and apoptosis at a post-mitochondrial level. J Cell Biol 151: 483-494, 2000.

19. Bondar VM, Sweeney-Gotsch B, Andreeff M, Mills GB and McConkey DJ: Inhibition of the phosphatidylinositol 3'-kinaseAKT pathway induces apoptosis in pancreatic carcinoma cells in vitro and in vivo. Mol Cancer Ther 1: 989-997, 2002.

20. Ng SSW, Tsao MS, Chow S and Hedley DW: Inhibition of phosphatidylinositide 3-kinase enhances gemcitabine-induced apoptosis in human pancreatic cancer cells. Cancer Res 60: $5451-5455,2000$ 